\title{
KOMPETENSI MENGAJAR MAHASISWA PPL PRODI PENDIDIKAN JASMANI FKIP UNTAN TA 2019/ 2020 KOTA PONTIANAK
}

\author{
Retno Priyadi, Victor G Simanjuntak, Fitriana Puspa Hidasari. \\ Program Studi Pendidikan Jasmani FKIP Untan Pontianak \\ Email:retnopriyadi10@gmail.com
}

\begin{abstract}
The problem in this study is how to teach competence students practice field experience physical education study programs 2019/2020 in junior high school and high school at Pontianak city. This research is a quantitative study with survey method. Data collection techniques by giving questionnaires. The population in this study was 39 schools. Data analysis using a percentage. Based on the results of research that has been done, the result obtained that the teaching competencies of students in the field study program practice physical education 2019/2020 in junior and high school at Pontianak city have 3 categories. First, category is a very good category with a percentage of $89,74 \%$. The second category is a good category is 7,69\%. The third category is $2,56 \%$ good enough. While students in bad catagories do not exist. This means competence students practice field experience in secondary and middle schools senior high school in Pontianak are classified as good.
\end{abstract}

\section{Keywords : Physical Education, Survey, Teaching Skill}

\section{PENDAHULUAN}

Pendidikan adalah pengalamanpengalaman belajar terprogram dalam bentuk pendidikan formal, non-formal, dan informasi di sekolah, dan luar sekolah yang berlangsung seumur hidup yang bertujuan optimalisasi pertimpangan kemampuankemampuan individu, agar dikemudian hari dapatmemainkan peranan hidup secara. Sedangkan definisi sempit pendidikan yaitu, pendidikan adalah pengajaran yang diselenggarakan disekolah sebagai lembaga pendidikan formal. Pendidikan adalah segala dipengaruhi yang diupaya sekolah terhadap anak dan remaja yang diserahkan kepadanya agar mempunyai kemampuan yang sempurna dan kesadaran penuh terhadap hubunganhubungan dan tugas-tugas sosial mereka. Ada pun definisi luas dan definisi sempit tujuan pendidikan, dengan demikian guru dapat mengetahui pencapaian indikator yang telah ditentukan. pendidikan menurut Redja Mudyahardjo (2010:11), definisi luas pendidikan adalah "usaha sadar yang dilakukan oleh keluarga, masyarakat, dan pemerintah, melalui kegiatan bimbingan, pengajaran, dan latihan, yang berlangsung disekolah dan luar sekolah sepanjang hayat, untuk mempersiapkan peserta didik agar dapat memainkan peranan dalam berbagai lingkungan hidup secara tepat di masa yang akan datang"

Menurut Suardi (2012:6), tujuan pendidikan adalah "seperangkat hasil pendidikan yang dicapai oleh peserta didik setelah diselenggarakan kegiatan pendidikan". Dari penjelasan ini dapat dipahami bahwa seluruh kegiatan pendidikan, yakni bimbingan pengajaran atau latihan, diarahkan untuk mencapai Pendidikan jasmani adalah suatu bentuk pendidikan yang tersusun secara sistematis dan terarah melalui aktifitas 
jasmani yang didalamnya memuat unsurunsur kongnitif, afektif, dan pisikomotor dalam rangka menigkatkan individu secara utuh. Melalui pendidikan jasmani inilah diharapkan siswa mampu memperoleh pengalaman dalam hal sikap, pemikiran yang sportif, jujur, saling berbagi, disiplin maupun tanggung jawab (Giri Wiarto, 2015:2). Menurut Dini Rosdiani (2012:23) pendidikan jasmani adalah proses pendidikan yang memanfaatkan aktivitas jasmani yang direncanakan secara sistematik bertujuan untuk mengembangkan dan meningkatkan individu secara organik, neuromuskuler, perseptual kongnitif, dan emosional, dalam kerangka sistem pendidikan nasional. Di dalam dunia pendidikan khususnya penddikan jasmani, didalam proses pembelajaran banyak hal yang akan dikembangkan terhadap kemampuan peserta didik baik yang berkenaan dengan sikap, pengetahuan, perkembangan sistem perototan, dan pengembangan skil peserta didik.

Kinerja guru adalah hasil yang dapat dicapai oleh seorang guru di lembaga pendidikan sesuai dengan tugas dan tanggung jawab dalam mencapai tujuan pendidikan. Keberhasilan seorang guru harus memenuhi kriteria yang telah ditetapkan. Apabila guru telah memenuhi kriteria tersebut berarti seorang guru tersebut dikatakan berhasil dan memiliki kualitas yang baik. Sebaliknya apabila guru belum memenuhi kriteria yang baik maka guru belum dapat dikatakan berhasil. Guru di dalam kegiatan pembelajaran akan menjadi model bagi peserta didik yang akan mengamati, memperhatikan, serta meniru bahkan guru dinilai oleh peserta didik sendiri, peserta didik juga akan menilai keterampilan, penguasaan pada materi yang disampaikan oleh guru, keterampilan yang diajarkan, perhatiannya guru terhadap peserta didiknya, peserta didik juga akan menilai sikap dan perilaku serta kepribadian guru saat mengajar, menilai bagaimana cara guru berinteraksi kepada peserta didiknya.

Mengingat pentingnya peranan guru dalam upaya meningkatkan mutu pendidikan maka Pendidikan Jasmani FKIP UNTAN Pontianak sebagai salah satu lembaga pendidikan yang mencetak calon guru, telah mengarahkan mahasiswa-mahasiswinya agar memiliki pengalaman dalam mengajar dilapangan. Salah satu cara dengan membekali para mahasiswa-mahasiswi dengan seperangkat kompetensi bagi para calon guru melalui Program Pengalaman Lapangan (PPL). Program kegiatan PPL terintregrasi dan saling mendukung satu dengan yang lainnya untuk mengembangkan kompetensi mahasiswa sebagai calon guru atau tenaga kependidikan. Mata kuliah PPL mempunyai sasaran masyarakat sekolah, baik dalam kegiatan yang terkait dengan pembelajaran maupun kegiatan yang mendukung berlangsungnya pembelajaran. Program Pengalaman Lapangan (PPL) merupakan mata kuliah wajib berbobot 4 SKS yang wajib diselesaikan oleh semua mahasiswa Program Studi Pendidikan Sarjana Strata Satu (S1), praktik ini untuk mengaplikasikan semua pengetahuan yang sudah didapatkan mahasiswa selama perkuliahan sesuai dengan bidangnya, di sekolah-sekolah yang digunakan untuk melaksanakan PPL. Khusus mahasiswa Program Studi Pendidikan Jasmani, FKIP Universitas Tanjungpura, PPL dilakukan di Sekolah Se-Kota Pontianak. Program Pengalaman lapangan merupakan suatu langkah strategis untuk mengembangkan empat kompetensi dasar sebagai seseorang pendidik menuju era tenaga kependidikan yang professional. Keberhasilan mahasiswa dalam melaksanakan PPL dimulai dari observasi orientasi pengamatan mahasiswa 
PPL dan penangkapan objek-objek melalui panca indra terhadap kinerja mahasiswa PPL sebagai calon guru. Persepsi peserta didik di pengaruhi dari bagaimana penampilan mahasiswa PPL sejauh mana ditunjukkan dalam melaksanakan proses pembelajaran di sekolah. Penampilan atau kinerja mahasiswa PPL diharapkan mampu menerapkan teoriteori yang telah diperoleh semasa duduk di bangku perkuliahan dalam rangka memperoleh kompetensi guru yang sebenarnya. Persepsi yang baik akan berdampak positif bagi mahasiswa PPL yaitu akan menjadikan koreksi dan acuan selanjutnya dalam mengarungi dunia pendidikan. Sebagaimana khususnya untuk mahasiswa program pengalaman lapangan (PPL) Universitas Tanjungpura Pontianak juga dituntut untuk menguasai 4 kompetensi guru yang harus dimiliki dalam peraturan pemerintah nomor 14 Th 2005 tentang Guru dan Dosen, kompetensi tersebut merupakan kompetensi pedagogik, kompetensi kepribadian, kompetensi sosial dan kompetensi profesional.

Praktek Pengalaman Lapangan (PPL) merupakan salah satu mata kuliah yang wajib diikuti oleh mahasiswa FKIP Untan Pontianak. Praktek Pengalaman Lapangan dilaksanakan untuk memenuhi persyaratan dan melengkapi tugas serta ujian mata kuliah Praktek Pengalaman Lapangan di FKIP Untan Pontianak. Untuk meningkatkan sumber daya yang berkualitas, maka dalam pelaksanaan Praktek Pengalaman Lapangan (PPL) mahasiswa dibekali terlebih dahulu dengan mata kuliah pengajaran mikro (micro teaching) dan pengalaman pendidikan lain yang diperoleh selama masa perkuliahan. Seorang pendidik selain mengajarkan materi pengajaran yang merupakan transfer ilmu yang dimiliki kepada peserta didik juga bertanggung jawab dalam membina dan mendidik agar menjadi kader bangsa yang cerdas dan siap bersaing dalam segala sendi kehidupan. Seorang pendidik selain dituntut untuk harus menguasai materi yang diajarkan juga harus menguasai lingkungan tempat di mana ia bertugas, hal ini bertujuan agar terjadi proses pembelajaran seperti yang diharapkan dapat tercapai.

Sejalan dengan hakekatnya sebagai tempat pembentukan kemampuan keguruan melalui praktek langsung di lapangan, makan komponen utama Praktek Pengalaman Lapangan (PPL) adalah latihan-latihan, baik katihan dalam situasi yang dikondisikan sedemikian rupa maupun latihan di dalam situasi yang memang alamiah dan nyata. Berdasarkan hal-hal di atas maka program Praktek Pengalaman Lapangan (PPL) lebih dititik beratkan kepada latihan-latihan proses belajar mengajar maupun latihan interaksi terhadap kelas secara mandiri dan inisiatif. Standar kompetensi mata kuliah PPL dirumuskan dengan mengacu pada tuntutan empat kompetensi guru baik dalam konteks pembelajaran maupun dalam konteks kehidupan guru sebagai anggota masyarakat. Empat kompetensi guru yang dimaskud adalah kompetensi pedagogik, kompetensi kepribadian, kompetensi profesional, dan kompetensi sosial. Adapun hal-hal yang menjadi pertimbangan pengambilan judul penelitian adalah sebagai berikut: (1) Belum diketahui kompetensi mahsiswa PPL Prodi Pendidikan Jasmani FKIP UNTAN Pontianak TA 2019/2020, (2) Belum diketahui tingkat kepuasan pihak sekolah terhadap kinerja mahsiswa PPL Prodi Pendidikan Jasmani FKIP UNTAN Pontianak TA 2019/2020, dan (3) Belum diketahui tingkat kepuasan peserta didik terhadap kinerja mahasiswa PPL Prodi Pendidikan Jasmani FKIP UNTAN Pontianak TA 2019/2020. Berdasarkan paparan tersebut, maka peneliti ingin mengetahui "Kompetensi Mengajar Mahasiswa PPL Prodi Pendidikan Jasmani FKIP UNTAN Pontianak TA 2019/2020 SeKota Pontianak". 


\section{METODE PENELITIAN}

Metode yang digunakan oleh penulis dalam penelitian ini adalah metode deskriptif. Menurut Nawawi (2015: 67), metode deskriptif adalah prosedur pemecahan masalah yang diselidiki dengan menggambarkan/ melukiskan keadaan subyek/obyek pada saat sekarang berdasarkan fakta-fakta yang tampak, atau sebagaimana adanya. Penelitian deskriptif adalah penelitian yang dimaksudkan untuk menyelidiki keadaan, kondisi atau hal-hal lain yang sudah disebutkan, yang hasilnya dipaparkan dalam bentuk penelitian, (Suharsimi Arikunto, 2010: 3). Bentuk penelitian yang digunakan dalam penelitian ini adalah survey (survey Studies), yang bertujuan untuk mengetahui Kompetensi Mahasiswa Praktek Pengalaman Lapangan Program Studi Pendidikan Jasmani tahun 2019.

Populasi dalam penelitian ini adalah seluruh mahasiswa PPL Pendidikan Jasmani Fakultas Keguruan dan Ilmu
Pendidikan Universitas Tanjungpura di kota Pontianak tahun 2019 yang berjumlah 40 sekolah sesuai dengan observasi yang dilakukan peneliti. Sedangkan sampel dalam penelitian ini adalah seluruh mahasiswa pendidikan jasmani yang sedang melakukan PPL pada tahun 2019 yang berada di Kota Pontianak pada tingkat Sekolah Menengah Atas dan sederajat baik swasta maupun negeri sebanyak 48 orang. Penelitian ini dilaksanakan pada tanggal 5 September 2019 s/d 20 Oktober 2019. Tempat pelaksanan penelitian ini akan dilakukan di sekolah SMA dan SMP sederajat yang berada di Kota Pontianak yang menjadi lokasi PPL periode Agustus-November 2019.

Teknik pengumpulan data pada penelitian ini menggunakan teknik survey. Sebelum dilakukan penelitian, terlebih dahulu dilakukan uji vaiditas dan uji reabilitas. Berikut jumlah soal valid dan tidak valid berdasarkan uji validitas dan uji reabilitas:

Tabel 1. Data hasil uji validitas

\begin{tabular}{ccc}
\hline No & Keterangan & \multicolumn{1}{c}{ Nomor Soal } \\
\hline $\mathbf{1}$ & Valid & $1,3,4,5,6,7,8,9,10,12,13,14,15,16$, \\
& & $17,18,20,21,22,23,26,27,28,29,30$, \\
& & $31,33,34,35,36,39,42,43,44,45,46$, \\
& & $47,48,49,50$ \\
\hline $\mathbf{2}$ & Tidak Valid & $2,11,19,24,25,32,37,38,40,41$ \\
\hline
\end{tabular}

Sumber : hasil data penelitian

Tabel 2. Data hasil uji reabilitas

\begin{tabular}{ccccc}
\hline $\begin{array}{c}\text { Jumlah } \\
\text { Responden }\end{array}$ & Butir Soal & $\begin{array}{c}\text { Jumlah } \\
\text { Varians }\end{array}$ & $\begin{array}{c}\text { Varians } \\
\text { Total }\end{array}$ & Reliabilitas \\
\hline 39 & 50 & 164,814 & 6,8020 & 1,01 \\
\hline
\end{tabular}

Sumber : hasil data penelitian 


\section{HASIL DAN PEMBAHASAN}

\section{Hasil}

Penelitian ini dilaksanakan dari tanggal 3 sampai 28 Februari 2020. Penelitian tersebut dilakukan di 15 Sekolah Menengah Atas (SMA) dan 24 Sekolah Menengah Pertama (SMP) di kota Pontianak. Pengambilan data diperoleh dari pengisian angket yang berjumlah 50 butir soal yang memiliki pilihan jawaban yaitu (1) Sangat Baik dengan nilai 4, (2) Baik dengan nilai 3,
(3) Cukup baik dengan nilai 2, dan (4) Tidak baik dengan nilai 1 . Maka dengan demikian skor maksimal yang dapat diperoleh adalah 200 dan skor minimal yang dapat diperoleh adalah 50. Hasil analisis dapat dilihat pada tabel di bawah ini:

Tabel 3. Hasil Analisis Kompetensi Mengajar Mahasiswa PPL Prodi Pendidikan Jasmani FKIP UNTAN PontianakTA 2019/2020

\begin{tabular}{ccccc}
\hline No & Rentang Nilai & Frekuensi & Persentase (\%) & Kategori \\
\hline $\mathbf{1}$ & $164-200$ & 35 & 89,74 & Sangat Baik \\
\hline $\mathbf{2}$ & $126-163$ & 3 & 7,69 & Baik \\
\hline $\mathbf{3}$ & $88-125$ & 1 & 2,56 & Cukup Baik \\
\hline $\mathbf{4}$ & $50-87$ & 0 & 0 & Tidak Baik \\
\hline & Jumlah & 39 & 100 & - \\
\hline
\end{tabular}

Sumber : hasil data penelitia

Berdasarkan tabel diatas, kompetensi mengajar mahasiswa PPL Prodi Pendidikan Jasmani FKIP Untan Pontianak tahun ajaran 2019/2020, didapat bahwa 35 orang terdapat pada rentang skor 138 sampai 200 sehingga 89,74\% dengan kategori "Sangat Baik". 3 orang terdapat pada rentang skor 126 sampai 163 sehingga 7,69\% dengan kategori "Baik". 1 orang terdapat pada

Tabel 4. Data Hasil Angket Kompetensi Pedagogik Mahasiswa PPL Program Studi Pendidikan Jasmani tahun 2019

\begin{tabular}{ccccc} 
No. & Rentang Skor & Kategori & Frekuensi & Persentase (\%) \\
\hline $\mathbf{1}$ & $51-64$ & Sangat Baik & 36 & $92 \%$ \\
\hline $\mathbf{2}$ & $38-50$ & Baik & 3 & $8 \%$ \\
\hline $\mathbf{3}$ & $25-37$ & Cukup & 0 & $0 \%$ \\
\hline $\mathbf{4}$ & 1224 & Tidak Baik & 0 & $0 \%$ \\
\hline Jumlah & & & 39 & $100 \%$ \\
\hline
\end{tabular}

rentang skor 88 sampai 125 sehingga 2,56\% dengan kategori "Cukup Baik" dan tidak satupun orang yang terdapat pada rentang skor 50 sampai 87 sehingga $0 \%$ dengan kategori "Tidak Baik". Hasil Analisis kompetensi mengajar mahasiswa PPL Prodi Pendidikan Jasmani FKIP Untan Pontianak tahun ajaran 2019/2020 terbagi ke dalam 4 indikator. Berikut hasil analisis masingmasing indikator: 
Berdasarkan tabel di atas, kompetensi mengajar mahasiswa PPL Prodi Pendidikan Jasmani FKIP UNTAN tahun 2018 berdasarkan indikator kompetensi $92 \%$. dikategorikan sangat baik., dan 3 mahasiswa PPL pada rentang skor 38 sampai 50 dengan persentase $8 \%$ dikategorikan baik dan tidak ada mahasiswa PPL yang tidak baik Tabel 5. Data Hasil Angket Kompetensi kepribadian Mahasiswa PPL Program
Studi Pendidikan Jasmani tahun 2019

\begin{tabular}{ccccc} 
No. & Rentang Skor & Kategori & Frekuensi & $\begin{array}{c}\text { Persentase } \\
(\mathbf{\%})\end{array}$ \\
\hline $\mathbf{1}$ & $35-44$ & Sangat Baik & 31 & $79 \%$ \\
\hline $\mathbf{2}$ & $27-34$ & Baik & 7 & $18 \%$ \\
\hline $\mathbf{3}$ & $19-26$ & Cukup & 1 & $3 \%$ \\
\hline $\mathbf{4}$ & $11-18$ & Tidak Baik & 0 & $0 \%$ \\
\hline Jumlah & & 39 & $100 \%$ & \\
\hline
\end{tabular}

Berdasarkan tabel di atas, kompetensi mengajar mahasiswa PPL Prodi Pendidikan Jasmani FKIP UNTAN tahun 2019 berdasarkan indikator kompetensi kepribadia, bahwa 31 mahasiswa PPL terdapat pada rentang skor 35 sampai 44 dengan persentase 79\% dikategorikan sangat baik, dan7 mahasiswa
PPL pada rentang skor 27 sampai 34 dengan persentase $18 \%$ dikategorikan baik, 1 mahasiswa PPL terdapat pada rentang skor

19 sampai 26 dengan persentase $3 \%$ dikategorikan cukup dan tidak ada mahasiswa PPL yang kompetensi kepribadian dikategorikan tidak baik.

Tabel 7. Data Hasil Angket Kompetensi profesional Mahasiswa PPL Program Studi Pendidikan Jasmani tahun 2019

\begin{tabular}{ccccc} 
No. & Rentang Skor & Kategori & Frekuensi & $\begin{array}{c}\text { Persentase } \\
(\boldsymbol{\%})\end{array}$ \\
\hline $\mathbf{1}$ & $24-32$ & Sangat Baik & 34 & $87 \%$ \\
\hline $\mathbf{2}$ & $18-23$ & Baik & 5 & $13 \%$ \\
\hline $\mathbf{3}$ & 1217 & Cukup & 0 & $0 \%$ \\
\hline $\mathbf{4}$ & 611 & Tidak Baik & 0 & $0 \%$ \\
\hline Jumlah & & & 39 & $100 \%$ \\
\hline
\end{tabular}

Berdasarkan tabel di atas, kompetensi mengajar mahasiswa PPL Prodi Pendidikan Jasmani FKIP UNTAN tahun 2019 berdasarkan indikator kompetensi profesional, bahwa 34 mahasiswa PPL terdapat pada rentang skor 24 sampai 32 dengan persentase $87 \%$ dikategorikan sangat baik, dan 5 mahasiswa PPL pada rentang skor 18 sampai 23 dengan persentase 13\% dikategorikan baik dan tidak ada mahasiswa PPL yang kompetensi profesional dikategorikan cukup dan tidak baik. 


\section{Tabel 7. Data Hasil Angket Kompetensi sosial Mahasiswa PPL Program Studi Pendidikan Jasmani tahun 2019}

\begin{tabular}{ccccc} 
No. & Rentang Skor & Kategori & Frekuensi & $\begin{array}{c}\text { Persentase } \\
(\mathbf{\%})\end{array}$ \\
\hline $\mathbf{1}$ & $17-20$ & Sangat Baik & 22 & $56 \%$ \\
\hline $\mathbf{2}$ & $13-16$ & Baik & 15 & $38 \%$ \\
\hline $\mathbf{3}$ & $9-12$ & Cukup & 2 & $5 \%$ \\
\hline $\mathbf{4}$ & $5-8$ & Tidak Baik & 0 & $0 \%$ \\
\hline Jumlah & & & 39 & $100 \%$ \\
\hline
\end{tabular}

Berdasarkan tabel di atas, kompetensi mengajar mahasiswa PPL Prodi Pendidikan Jasmani FKIP UNTAN tahun 2019 berdasarkan indikator kompetensi sosial, bahwa 22 mahasiswa PPL terdapat pada rentang skor 17 sampai 20 dengan persentase 56\% dikategorikan sangat baik, dan 15 mahasiswa PPL pada rentang skor 13 sampai 16 dengan persentase $38 \%$ dikategorikan baik, 2 mahasiswa PPL terdapat pada rentang 9 sampai 12 dengan persentase 5\% dikategorikan cukup dan tidak ada mahasiswa PPL yang kompetensi sosial dikategorikan tidak baik.

\section{Pembahasan}

Berdasarkan hasil analisis data penelitian di atas dapat diketahui bahwa kompetensi mengajar mahasiswa PPL Prodi Pendidikan Jasmani FKIP Untan Pontianak tahun ajaran 2019/2020 ketika berada di sekolah tergolong sangat tinggi yaitu 35 mahasiswa PPL dengan persentase 89,74\% dikategorikan sangat baik, 3 mahasiswa PPL dengan persentase $7,69 \%$ dengan kategori baik, 1 mahasiswa PPL dengan persentase 2,56\% dikategorikan cukup baik dan tidak satupun mahasiswa PPL yang berada di kategori tidak baik. Hal tersebut merupakan suatu nilai yang cukup membanggakan bagi Fakultas Keguruan dan Ilmu Pendidikan UNTAN khususnya Prodi Pendidikan Jasmani. Karena di dalam angket tercantum pertanyaanpertanyaan seputar kesiapan dalam mengajar, keterampilan dalam mengajar serta inovasi dalam mengajar yang dapat di rata-ratakan nilai keseluruhannya mendekati sempurna yaitu 3,32 dengan skor maksimal 4 .

\section{SIMPULAN DAN SARAN \\ Simpulan}

Hasil analisis data dan pembahasan tentang kompetensi mengajar mahasiswa PPL Prodi Pendidikan Jasmani FKIP Untan Pontianak tahun ajaran 2019/2020 menunjukkan bahwa kompetensi mengajar mahasiswa PPL Prodi Pendidikan Jasmani FKIP Untan Pontianak tahun ajaran 2019/2020 berada pada kategori sangat baik dengan persentase $89,74 \%$ yaitu 35 mahasiswa PPL, kompetensi mengajar mahasiswa PPL Prodi Pendidikan Jasmani FKIP Untan Pontianak tahun ajaran 2019/2020 berada pada kategori baik dengan persentase 7,69\% yaitu 3 mahasiswa PPL, kompetensi mengajar mahasiswa PPL Prodi Pendidikan Jasmani FKIP Untan Pontianak tahun ajaran 2019/2020 berada pada kategori cukup baik dengan persentase $2,56 \%$ yaitu 1 mahasiswa PPL dan kompetensi mengajar mahasiswa PPL Prodi Pendidikan Jasmani FKIP Untan Pontianak tahun ajaran 2019/2020 berada pada kategori tidak baik dengan persentase $0 \%$ yaitu 0 mahasiswa 


\section{Saran}

Berdasarkan hasil penelitian yang telah disimpulkan di atas, maka dapat dikemukakan saran sebagai berikut: (1) Bagi Mahasiswa PPL Prodi Pendidikan Jasmani FKIP Untan agar mempertahankan kualitas atau bahkan menambah kualitas dalam mengajar saat maupun sesudah PPL, dan (2) Bagi Universitas Tanjungpura khususnya Prodi Pendidikan Jasmani agar dijadikan evaluasi untuk calon mahasiswa PPL selanjutnya

\section{DAFTAR RUJUKAN}

Ali, M. (2007). Ilmu Dan Aplikasi Pendidikan. Bandung: PT IMTIMA.

Alma. (2008). Guru Profesional Menguasai Metode dan Keterampilan Mengajar. Bandung: Alfabeta.

Ates. (2013). Kompetensi Pedagogik Guru Pendidikan Jasmani Pada Smp Negeri Se-Kecamatan Teriak Kabupaten Bengkayang. Skripsi. Pontianak: Universitas Tanjungpura
Dian, A. (2016). Survey Tingkat Keaktivan Peserta Didik Dalam Mengikuti Pembelajaran Penjasorkes Di SMA Muhammadiyah 2 Pontianak Tahun Ajaran 2015/2016. Skripsi. Pontianak: Universitas Tanjungpura.

Kadir, Abdul S. (2018). Mendidik Perspektif Psikologi. Yogyakarta: CV Budi Utama

Pujiati, E. (2017). Implementasi Kompetensi Pedagogik Dan Profesional Guru Terhadap Proses Pembelajaran Penjas Di Sekolah dasar Negeri SeKecamatan Kretek Kabupaten Bantul.Skripsi. Yogyakarta: Universitas Negeri Yogyakarta

Rosdiani, D. (2012). Model Pembelajaran Langsung Dalam Pendidikan Jasmani dan Kesehatan. Bandung: Alfabeta.

Victor, G, S. (2011). Analisis Sistem Pengeembangan Kurikulum Pendidikan Jasmani SD. Pontianak: FKIP Untan.

Wiarto, G. (2015). Inovasi Pembelajaran Dalam Pendidikan Jasmani. Yogyakarta:Laksita 